\title{
NGHIÊN CỨU TÁC ĐộNG CHÍNH SÁCH TRÁCH NHIỆM XÃ HỘI ĐẾN THƯONG HIỆU CỦA DOANH NGHIỆP TẠI THÀNH PHỐ HỒ CHÍ MINH
}

\author{
NGUYEN THI VAN ${ }^{1}$, NGUYEN VAN PHU ${ }^{1}$, MAI PHU HOP ${ }^{2}$ \\ ${ }^{1}$ Truờng Đại học Công nghiệp Thành phố Hồ Chí Minh, \\ ${ }^{2}$ Truoòng Đại học Cần Tho; \\ nguyenthivan@iuh.edu.vn,nguyenvanphu@iuh.edu.vn,mphop@ctu.edu.vn
}

Tóm tắt. Nghiên cứu này được thực hiện nhằm phân tích sự tác động chính sách xã hội của doanh nghiệp đến thương hiệu của doanh nghiệp tại thành phố Hồ Chí Minh từ đó xác định các nhân tố ảnh hưởng và trọng số của từng nhân tố, dùng làm cơ sở để nhóm tác giả đề xuất giải pháp nhằm nâng cao thương hiệu cho doanh nghiệp tại TPHCM. Sử dụng phương pháp nghiên cứu định tính và định lượng, nhóm tác giả tiến hành khảo sát 245 người với 26 biến quan sát nhằm mục đích xác định các nhân tố tác động đến thương hiệu của doanh nghiệp tại TPHCM. Kết quả nghiên cứu cho thấy có 05 nhân tố tác động như sau: trách nhiệm về kinh tế, trách nhiệm về pháp luật, trách nhiệm về đạo đức, trách nhiệm về từ thiện, và trách nhiệm về môi trường tác động tích cực đến thương hiệu của doanh nghiệp tại TPHCM.

Từ khóa. Trách nhiệm xã hội doanh nghiệp, thương hiệu doanh nghiệp, sản phẩm, chính sách xã hội của doanh nghiệp, thành phố Hồ Chí Minh.

\section{THE INFLUENCE OF CORPORATE SOCIAL RESPONSIBILITY POLICIES ON THE CORPORATE BRANDS IN HO CHI MINH CITY}

\begin{abstract}
This research was conducted to analyze the influence of Corporate Social Responsibility (CSR) policies on corporate brands in Ho Chi Minh City and identify influencing factors as well as their weights. The results are used for suggesting solutions to develop brands of businesses in Ho Chi Minh City. The qualitative and quantitative research methods were used to survey 245 people with 26 observed variables in order to determine factors affecting brands of businesses in Ho Chi Minh City. The results showed that five factors: economic responsibility, legal responsibility, ethical responsibility, responsibility for charity, and environmental responsibility influence corporate brands in Ho Chi Minh City.

Keywords. Corporate Social Responsibility, Corporate Brand, Product, Social Policy of Business, Ho Chi Minh City.
\end{abstract}

\section{GIỚI THIỆ}

Cùng với công cuộc đổi mới toàn diện đất nước, sự thành công trong việc đẩy nhanh tốc độ tăng trưởng kinh tế đang đặt ra cho Việt Nam nhiều vấn đề về môi trường và xã hội bức xúc. Chính những vấn đề đó đang đòi hỏi các chủ thể kinh tế, trong đó có cả các doanh nghiệp, phải có trách nhiệm để góp phần giải quyết, nếu không bản thân sự phát triển kinh tế sẽ không bền vững và sẽ phải trả giá đắt về môi trường và những vấn đề xã hội.

Ngày nay, trách nhiệm xã hội doanh nghiệp (TNXHDN) đã trở thành một trong những yêu cầu cấp thiết mà hầu hết các quốc gia và doanh nghiệp $(\mathrm{DN})$ trên thế giới phải tuân thủ. Đối với các nước phát triển, TNXHDN được xem là một trong những chiến lược quan trọng cho sự phát triển bền vững, là cơ sở giảm chi phí và tăng năng suất; tăng doanh thu, nâng cao giá trị thương hiệu và uy tín của $\mathrm{DN}$; thu hút được nguồn lao động giỏi; sản phẩm và hàng hóa dịch vụ dễ tiếp cận được với thị trường thế giới; bảo vệ tốt môi trường tự nhiên, môi trường xã hội... và nó cũng được xem là "triết lý" kinh doanh của các DN. Chính lý do đó, áp dụng TNXH đối với các DN là nguyên tắc bắt buộc. Đồng thời, những nước có nền kinh tế thị trường phát triển thì mỗi $\mathrm{DN}$ trong hoạt động kinh doanh luôn là một bộ phận hữu cơ của nền kinh tế xã hội, những hành vi quyết định hướng kinh doanh cũng như phương thức kinh doanh của họ đều tuân theo những tiêu chuẩn và quy định của xã hội trên cả phương diện luật pháp cũng như đạo đức. Trong đó, chuẩn mực đạo đức trở thành phẩm chất không thể thiếu đối với mỗi người kinh doanh và đối với từng $\mathrm{DN}$. Bên 
cạnh các chuẩn đạo đức, là hệ thống pháp luật hoàn chỉnh đã giữ vai trò chủ yếu trong việc ngăn chặn hoạt động kinh doanh vi phạm những chuẩn mực đạo đức. Hệ thống các thể chế, cùng đạo đức kinh doanh hoàn chỉnh và việc tuân thủ nghiêm túc chính là điều kiện để các DN dễ dàng thực hiện TNXH. Một doanh nghiệp sản xuất bao bì lớn của $\mathrm{Ba}$ Lan đã tiết kiệm được 12 triệu đô la Mỹ trong vòng 5 năm nhờ việc lắp đặt thiết bị mới, nhờ đó làm giảm $7 \%$ lượng nước sử dụng, $70 \%$ lượng chất thải nước và $87 \%$ chất thải khí. Chi phí sản xuất và năng suất lao động phụ thuộc chặt chẽ vào hệ thống quản lý nhân sự. Nếu một hệ thống quản lý nhân sự hiệu quả cũng giúp doanh nghiệp cắt giảm chi phí và tăng năng suất lao động đáng kể. Chế độ lương, thưởng hợp lý, môi trường lao động sạch sẽ và an toàn, các cơ hội đào tạo và chế độ bảo hiểm y tế và giáo dục tốt đều góp phần giảm tỷ lệ nhân viên nghỉ, bỏ việc, do đó cũng giảm chi phí tuyển dụng và đào tạo nhân viên mới.

Trong khi đó tại các nước đang phát triển, do hệ thống pháp luật chưa hoàn thiện nên cơ hội phát triển kinh tế và xã hội bị hạn chế bởi độc quyền, tham nhũng và những lợi ích nhóm... Vì lẽ đó, nên từ nhận thức cho đến thực hiện trách nhiệm đối với xã hội của các DN không phải là việc dễ dàng. Với Việt Nam, tuy là quốc gia đi sau trong việc tiếp cận vấn đề TNXHDN của thế giới, không phải ngẫu nhiên, trong những năm gần đây, trên sách báo và nhiều diễn đàn ở Việt Nam, thuật ngữ CSR đã và đang được sử dụng ngày càng phổ biến. Mặc dù đã có những thay đổi ngày càng tích cực hơn, thế nhưng cả về nhận thức lẫn thực tiễn thể hiện, cần thấy đây vẫn là vấn đề còn khá mới mẻ đối với không ít $\mathrm{DN}$. Phần nhiều $\mathrm{DN}$ nhận thức sai ý nghĩa và thực chất về TNXHDN - TNXH chỉ đơn giản là xây dựng hình ảnh của DN để thu hút các nhà đầu tư, khách hàng hoặc làm từ thiện. Do đó, có rất nhiều hành vi vi phạm của nhiều $\mathrm{DN}$ và để lại nhiều hậu quả ảnh hưởng xấu đến kinh tế - xã hội cũng như môi trường tự nhiên.

Tuy nhiên, có thể kết luận rằng các nhân tố thuộc trách nhiệm xã hội của doanh nghiệp (kinh tế, pháp luật, đạo đức, từ thiện và môi trường) tác động đến thương hiệu của doanh nghiệp kinh doanh tại VN nói chung và $\mathrm{TPHCM}$ nói riêng, nhiều $\mathrm{DN}$ tại $\mathrm{TPHCM}$ trong thời gian qua áp dụng $\mathrm{TNXH}$ và đã mang lại nhiều hiệu quả quan trọng, thực tiễn này được nhiều nhà khoa học, nhà nghiên cứu chứng minh. Trong khuôn khổ bài viết này nhóm tác giả sẽ tập trung nghiên cứu vấn đề "Chính sách trách nhiệm xã hội của doanh nghiệp tác động đến thương hiệu của doanh nghiệp tại Thành Phố Hồ Chí Minh”.

\section{CƠ SỞ LÝ THUYẾT}

Khái niệm trách nhiệm xã hội của doanh nghiệp (Corporate Social Responsibility) có lịch sử phát triển lâu dài và nội hàm của khái niệm này cũng rất đa dạng. Nó là mối quan tâm của cộng đồng $\mathrm{DN}$ đối với xã hội và xã hội đối với $\mathrm{DN}$ trong nhiều thế kỷ. Quay về lịch sử hình thành, thì nó chính thức xuất hiện và sử dụng phổ biến vào những năm 50 của thế kỷ $X X$. Tuy nhiên, thuật ngữ này đã manh nha sớm hơn, cụ thể nó đã được đề cập vào những năm 1930 - 1940, trong các tác phẩm của Chester Barnard 1938 [1]"Chức năng của điều hành" (The Functions of the Executive), J. M. Clark's 1939 "Kiểm soát xã hội của các doanh nghiệp" (Social Control of Business) [2], và Theodore Kreps's 1940 "Đo lường hiệu quả xã hội của các doanh nghiệp" (Measurement of the Social Performance of Business) [3], các tác phẩm đã đề cập đến một số mặt vấn đề TNXHDN. Tuy nhiên, giai đoạn này nội hàm còn hạn chế và chưa phải là chủ đề được nhiều người quan tâm. Sang những năm 1950 nền kinh tế phát triển mạnh, sự tích lũy tư bản đã hình thành những tập đoàn, tổng công ty có quy mô lớn. Tính chất của nền sản xuất kinh doanh hiện đại, với việc sử dụng lao động theo kiểu dây chuyền của mô hình Fredericl Winslow Taylor và Henry Ford trong quản trị DN và đặc biệt là sự tiêu ngốn một lượng tài nguyên khổng lồ cùng với việc phát thải lượng phế thải cũng tương tự là nguyên nhân của những mối hiểm họa hủy hoại sinh quyển, sự gia tăng tình trạng bất bình đẳng đe dọa kết cẩu xã hội, tổn hại đến sức khỏe cộng đồng... Mặt khác, chính sự phản ứng của các hội đoàn, tổ chức phi chính phủ, của xã hội dân sự nói chung, đã tạo nên trào lưu xã hội gây áp lực khiến các DN - đặc biệt là các tập đoàn, các công ty đa quốc gia phải có hành động thể hiện trách nhiệm của mình với xã hội. Trước thực tiễn đó đòi hỏi cần phải có những cách thức giải thích mới về TNXHDN, và năm 1953 Howard R. Bowen (1908-1989) [4] công bố quyển sách mang tính bước ngoặt: Social Responsibilities of the Businessman Trách nhiệm xã hội của doanh nhân. Nội dung là nhằm tuyên truyền và kêu gọi người quản lý tài sản không làm tổn hại đến các quyền và lợi ích của người khác, kêu gọi lòng từ thiện nhằm bồi hoàn những thiệt hại mà các $\mathrm{DN}$ gây ra cho xã hội. Tác phẩm đã đánh dấu sự khởi đầu của thời kỳ hiện đại về cách hiểu cũng như những luận giải về khái niệm TNXHDN. Ngoài ra có các tác giả Wood's (1991), Carroll (1979), Porter và Kramer (2002), Kotle và Lee (2005); Shafiqur Rahman (2011) Henri và Ane (2012), Trang, N. T. T. 
(2012) [5] [6] v.v. Và kể từ đó cho đến nay đã có nhiều cách định nghĩa của các học giả khác nhau về thuật ngữ này, mỗi chính phủ, tổ chức, công ty, nhà nghiên cứu nhìn nhận TNXHDN dưới những góc độ và quan điểm riêng, phụ thuộc vào điều kiện luật pháp, đặc điểm và trình độ phát triển văn hóa của mình. Thông qua nhiều khái niệm TNXHDN thì theo tôi có những điểm cơ bản sau:

Một là, mỗi DN có cách trả lời độc đáo riêng, tùy thuộc vào năng lực cốt lõi của nó và lợi ích với các bên liên quan, phụ thuộc vào truyền thống văn hóa của quốc gia yêu cầu đối với các DN.

Hai là, TNXHDN về cơ bản là một triết lý hay một tầm nhìn về mối quan hệ của $\mathrm{DN}$ và xã hội, một trong những yêu cầu lãnh đạo thực hiện và duy trì nó theo thời gian.

Ba là, TNXHDN được cải tiến liên tục, không phải là một mốt nhất thời, bắt đầu ít và phát triển mở rộng theo thời gian.

Bốn là, nó gắn bó chặt chẽ với lợi nhuận, không thể có TNXH nếu không có lợi nhuận. Do đó, TNXH lớn nhất của DN là làm để được lợi nhuận.

Năm là, bên cạnh lợi nhuận, để phát triển DN phù hợp với pháp luật hiện hành thì đều phải gắn kết với lợi ích phát triển chung của cộng đồng xã hội. Hay hiệu quả kinh doanh để phát triển DN phải đóng góp cho cân bằng, hài hòa với mục tiêu phát triển xã hội. Đây là một trong những yêu cầu cơ bản để $\mathrm{DN}$ phát triển bền vững.

Trách nhiệm xã hội của doanh nghiệp đã trở thành văn hóa của DN và là phương châm sống của nhiều doanh nhân, nhà sáng lập. Năm 2010, Bill Gates đã hợp tác với tỷ phú Warren Buffett phát động chiến dịch mang tên Giving Pledge (Cam kết hiến tặng) nhằm nỗ lực thuyết phục những người giàu có nhất nước Mỹ cam kết hiến tặng ít nhất phân nửa tài sản cho các tổ chức từ thiện. Bản thân Bill Gates cũng cam kết sẽ hiến tặng gần như toàn bộ tài sản của mình để làm từ thiện. Ngày 1/12/2015 tỷ phú trẻ của Facebook, Mark Zuckerberg cũng tuyên bố sẽ hiến số tài sản 45 tỷ USD, tương đương $99 \%$ tổng tài sản trong suốt cuộc đời mình để kêu gọi những người khác cải thiện cuộc sống vì thế hệ tương lai [7]. Các doanh nghiệp "cho" nhưng thực chất họ lại "được nhận”, thậm chí doanh nghiệp hay cá nhân này còn nhận lại nhiều hơn sau khi đã cho.

\section{Mô hình nghiên cứu}

Căn cứ vào các kết quả nghiên cứu khoa học của các tác giả như (H.R.Bowen, 1953, Archie. B Carroll, 1979; Keith Davis, 1973; Prakash \& Sethi, 1975, Jimmy \& L.A, 2012) học thuyết marketing quan hệ của David Lam (2012) học thuyết marketing 2.0 của Philip Kotler (2010) [8] và nhiều kết quả nghiên cứu khoa học liên quan như nểu trên, tác giả tham khảo ý kiến của các chuyên gia để xây dựng mô hình nghiên cứu và tiến hành nghiên cứu sơ bộ trước khi đề xuất một mô hình nghiên cứu chính thức như sau:

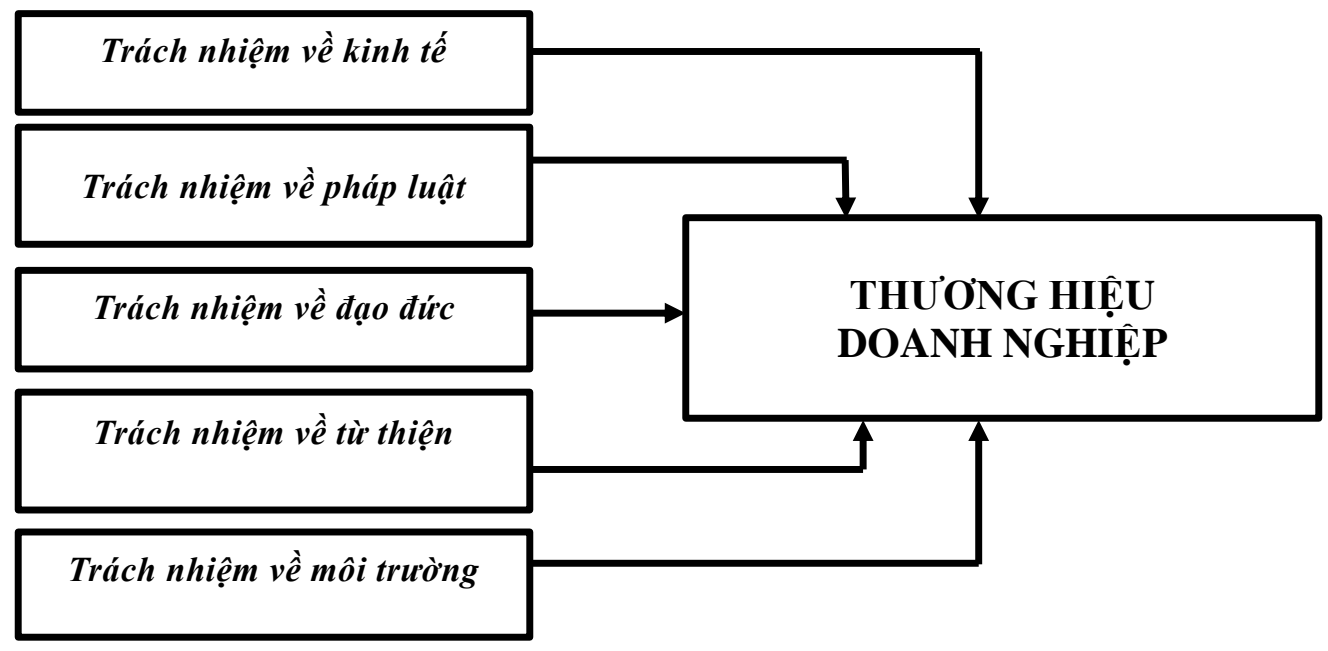

Hình 1. Mô hình nghiên cứu 
Các giải thuyết cho nghiên cứu:

H1: "Trách nhiệm về kinh tế" có tác động đến thương hiệu của doanh nghiệp tại TPHCM

H2: "Trách nhiệm về pháp luật" có tác động đến thương hiệu của doanh nghiệp tại TPHCM

H3: "Trách nhiệm về đạo đức" có tác động đến thương hiệu của doanh nghiệp tại TPHCM

H4: "Trách nhiệm về từ thiện" có tác động đến thương hiệu của doanh nghiệp tại TPHCM

H5: "Trách nhiệm về môi trường" có tác động đến thương hiệu của doanh nghiệp tại TPHCM

\section{PHƯƠNG PHÁP VÀ KẾT QUẢ NGHIÊN CÚUU}

Nghiên cứu được thực hiện thông qua các giai đoạn:

Giai đoạn 1: thiết kế bảng câu hỏi và tiến hành khảo sát (sau khi khảo sát sơ bộ, tìm hiểu cơ sở lý thuyết và xây dựng mô hình nghiên cứu)

- Sử dụng thang đo Liker 5 mức độ, để đo lường thương hiệu doanh nghiệp kinh doanh tại TPHCM với các nhân tố mô hình ban đầu.

- Mẫu nghiên cứu: có 245 bảng câu hỏi được phát ra, thu về 238 bảng câu hỏi được phản hồi, sau khi loại đi các phiếu trả lời không đạt yêu cầu, còn lại 222 phiếu. Như vậy cơ sở dữ liệu đưa vào và xử lý dữ liệu và phân tích là 222 mẫu nghiên cứu (đạt tỷ lệ 90, 6\%)

Giai đoạn 2: xử lý số liệu và thống kê kết quả

Nghiên cứu sử dụng phương pháp định lượng, tiến hành đánh giá độ tin cậy của thang đo bằng hệ số Cronbach alpha, phân tích nhân tố khám phá (EFA), theo Hoàng trọng và Chu Nguyễn Mộng Ngọc (2008) [9] cho rằng mẫu ít nhất cũng bằng 4 hoặc 5 lần số biến quan sát cần tiến hành phân tích nhân tố, còn theo Hair và ctg (1998) [10] để có thể phân tích phân tích nhân tố khám phá (EFA) cần thu thập bộ dữ liệu với ít nhất 5 mẫu trên 1 biến quan sát (26x5=130 mẫu). Mẫu được chọn theo phương pháp chọn mẫu thuận tiện theo điều kiện gạn lọc những khách hàng có kiến thức về kinh tế, hiểu biết về chính sách xã hội của doanh nghiệp tại TPHCM.

Kết quả nghiên cúu

Bảng 3.1. Mô tả mẫu nghiên cứu

\begin{tabular}{|l|l|c|c|}
\hline \multicolumn{1}{|l|}{ Đặc điểm } & Tần suất & Phần trăm (\%) \\
\hline \multirow{5}{*}{ Giới tính } & Nam & 138 & 62.2 \\
\cline { 2 - 4 } & Nữ & 84 & 37.8 \\
\cline { 2 - 4 } & Tổng & $\mathbf{2 2 2}$ & $\mathbf{1 0 0}$ \\
\cline { 2 - 4 } & $18-30$ & 167 & 75.2 \\
\cline { 2 - 4 } & $30-45$ & 28 & 12.6 \\
\cline { 2 - 4 } & $45-60$ & 22 & 10 \\
\cline { 2 - 4 } & Trên 60 & 5 & 2.2 \\
\cline { 2 - 4 } & Tổng & $\mathbf{2 2 2}$ & $\mathbf{1 0 0}$ \\
\hline \multirow{5}{*}{ Trình độ học vấn } & Trung học & 5 & 2.3 \\
\cline { 2 - 4 } & Trung cấp & 5 & 2.3 \\
\cline { 2 - 4 } & Cao đẳng & 49 & 22.0 \\
\cline { 2 - 4 } & Đại học & 2 & 72.5 \\
\cline { 2 - 4 } & Sau đại học & $\mathbf{2 2 2}$ & 0.9 \\
\cline { 2 - 4 } & Tồng & & $\mathbf{1 0 0}$ \\
\hline
\end{tabular}

Kết quả thống kê cho thấy tỉ lệ giới tính, độ tuổi, trình độ học vấn của những người được khảo sát có sự chênh lệch. Trong đó độ tuổi được tập trung vào khoảng từ 18 - 45 vì đây là độ tuổi có kinh nghiệm và những kiến thức nhất định về uy tín thương hiệu của DN. 
Bảng 3.2. Kiểm định giá trị trung bình cho các biến quan sát

\begin{tabular}{|c|c|c|}
\hline Biến quan sát & $\mathbf{N}$ & Trung bình \\
\hline $\begin{array}{l}\text { Doanh nghiệp ứng dụng công nghệ thông tin nhằm giảm chi phí và thời gian phục vụ } \\
\text { trực tiếp khách hàng }\end{array}$ & 222 & 3.36 \\
\hline $\begin{array}{l}\text { Doanh nghiệp này thường xuyên tăng cường công tác xúc tiến quảng bá trên mạng xã } \\
\text { hội nhằm giảm ngân sách quảng cáo, tiếp thị. }\end{array}$ & 222 & 3.33 \\
\hline Doanh nghiệp này duy trì lợi thế cạnh tranh tốt & 222 & 3.34 \\
\hline $\begin{array}{l}\text { Doanh nghiệp này có nhiều chính sách cải thiện hiệu quả hoạt động kinh doanh và } \\
\text { quản trị rủi ro }\end{array}$ & 222 & 3.26 \\
\hline Doanh nghiệp này chấp hành pháp luật và thực hiện tốt các quy định của địa phương & 222 & 3.48 \\
\hline Doanh nghiệp này có nhận thức về pháp luật tốt & 222 & 3.40 \\
\hline $\begin{array}{l}\text { Doanh nghiệp này khuyến khích nhân viên của mình làm việc theo đúng quy định của } \\
\text { pháp luật }\end{array}$ & 222 & 3.57 \\
\hline Doanh nghiệp này có nhiều hoạt động phổ biến, tuyên truyền pháp luật tốt & 222 & 3.43 \\
\hline Doanh nghiệp này cung cấp đúng dịch vụ như đã cam kết & 222 & 3.35 \\
\hline Doanh nghiệp này có chất lượng sản phẩm/ dịch vụ tốt & 222 & 3.20 \\
\hline Doanh nghiệp cung cấp thông tin trung thực trong các chương trình quảng cáo & 222 & 3.04 \\
\hline $\begin{array}{l}\text { Doanh nghiệp này coi trọng các giá trị đạo đức trong kinh doanh hơn những lợi ích } \\
\text { nhất thời khi giải quyết sự cố phàn nàn từ phía khách hàng }\end{array}$ & 222 & 3.13 \\
\hline Doanh nghiệp này có môi trường làm việc tốt cho người lao động & 222 & 3.18 \\
\hline Doanh nghiệp đối xử với khách hàng công bằng & 222 & 3.18 \\
\hline Lãnh đạo doanh nghiệp hòa đồng và vui vẻ với mọi người & 222 & 3.11 \\
\hline $\begin{array}{l}\text { Doanh nghiệp này thường tham gia các hoạt động từ thiện như giúp đỡ người khuyết } \\
\text { tật, trẻ em, người nghèo v.v }\end{array}$ & 222 & 2.98 \\
\hline $\begin{array}{l}\text { Doanh nghiệp này có nhiều hoạt động tài trợ giúp nâng cao nhận thức trong cộng } \\
\text { đồng }\end{array}$ & 222 & 3.00 \\
\hline $\begin{array}{l}\text { Doanh nghiệp này có nhiều đóng góp vào các dự án cải thiện "chất lượng cuộc sống" } \\
\text { của cộng đồng. }\end{array}$ & 222 & 3.06 \\
\hline Doanh nghiệp này có nhiều chương trình tài trợ học bổng cho cộng đồng & 222 & 3.03 \\
\hline $\begin{array}{l}\text { Doanh nghiệp này có nhiều hoạt động trong việc nâng cao nhận thức và bảo vệ môi } \\
\text { trường }\end{array}$ & 222 & 3.33 \\
\hline Doanh nghiệp này có không gian môi trường làm việc xanh, sạch & 222 & 3.39 \\
\hline $\begin{array}{l}\text { Doanh nghiệp này có môi trường làm việc an toàn (trang bị các thiết bị chữa cháy, lối } \\
\text { thoát hiểm, dụng cụ bảo hộ lao động v.v) }\end{array}$ & 222 & 3.32 \\
\hline Doanh nghiệp này có môi trường làm việc thân thiện với khách hàng & 222 & 3.18 \\
\hline Tôi đánh giá cao về thương hiệu của doanh nghiệp này & 222 & 3.18 \\
\hline Tôi sẽ tiếp tục là khách hàng của doanh nghiệp này & 222 & 3.30 \\
\hline Tôi sẽ giới thiệu người thân, bạn bè sử dụng dịch vụ của doanh nghiệp này & 222 & 3.23 \\
\hline
\end{tabular}


Kết quả kiểm định trung bình của các thang đo cho thấy rằng, hầu hết các thang đo đều có giá trị trung bình khá từ 2.98 đến 3.57. Thang đo "Trách nhiệm về kinh tế", các biến quan sát dao động từ 3.16 đến 3.36 và thang đo "Trách nhiệm về pháp luật", các biến quan sát dao động từ 3.40 đến 3.57 . Thang đo "Trách nhiệm về đạo đức" là khá thấp so với các thang đo còn lại, các biến quan sát dao động từ 3.04 đến 3.35. Như vậy, khách hàng chưa thật sự đánh giá cao về thái độ, trách nhiệm về đạo đức của các doanh nghiệp, đây là một trong những yếu tố cần được cải thiện để nâng cao uy tín thương hiệu cho doanh nghiệp TPHCM.

Bảng 3.3. Thống kê mô tả cho các biến định tính

\begin{tabular}{|c|c|c|c|}
\hline \multicolumn{2}{|l|}{ Đặc điểm } & Tần suất & Phần trăm \\
\hline \multirow{5}{*}{ Mức độ hiểu biết về trách nhiệm xã hội } & Hiểu rất rõ & 5 & 2.2 \\
\hline & Hiểu & 182 & 82 \\
\hline & Hiểu chút ít & 35 & 15.8 \\
\hline & Không hiểu gì & 0 & 0 \\
\hline & Tổng & 222 & 100 \\
\hline \multirow{5}{*}{ Số lần sử dụng sản phẩm, dịch vụ } & $1-2$ lần & 191 & 86 \\
\hline & $3-4$ lần & 21 & 9.5 \\
\hline & $5-6$ lần & 10 & 4.5 \\
\hline & Trên 6 lần & 0 & 0 \\
\hline & Tổng & 222 & 100 \\
\hline \multirow{4}{*}{ Thời gian là khách hàng của doanh nghiệp } & Dưới 1 năm & 81 & 36.4 \\
\hline & 1 - 3 năm & 118 & 53.2 \\
\hline & Trên 3 năm & 23 & 10.4 \\
\hline & Tổng & 222 & 100 \\
\hline
\end{tabular}

Kết quả nghiên cứu cho thấy số lần sử dụng dịch vụ ở doanh nghiệp phần lớn chỉ là $1-2$ lần và thời gian trở thành khách hàng của doanh nghiệp chủ yếu là $1-3$ năm cho thấy mức độ trung thành còn chưa cao. Điều này cho thấy các doanh nghiệp tại TPHCM cần cải thiện để nâng cao lòng trung thành của khách hàng.

\section{KẾT QUẢ KIỂM ĐỊNH ĐỘ TIN CẬY THANG ĐO:}

Bảng 3.4. Cronbach's Alpha

\begin{tabular}{|l|l|l|l|}
\hline BIẾN & Mã hóa & Nhân tố & Hệ số Cronbach’s Alpha \\
\hline \multirow{3}{*}{ Biến độc lập } & A & Trách nhiệm về kinh tế & 0,750 \\
\cline { 2 - 4 } & B & Trách nhiệm về pháp luật & 0,709 \\
\cline { 2 - 4 } & C & Trách nhiệm về đạo đức & 0,884 \\
\cline { 2 - 4 } & D & Trách nhiệm về từ thiện & 0,783 \\
\cline { 2 - 4 } & E & Trách nhiệm về môi trường & 0,814 \\
\hline Biến phụ thuộc & S & Đánh giá chung & 0,980 \\
\hline
\end{tabular}

Kết quả kiểm định thang đo cho thấy thang đo có độ chính xác khá cao với hệ số Cronbach's Alpha > 0,7 và các hệ số tương quan biến tổng của các biến đo lường yếu tố này đều đạt chuẩn cho phép $(>0,3)$, các thang đo đều được chấp nhận. Từ đây tiến hành phân tích nhân tố khám phá ở bước tiếp theo. 


\section{PHÂN TÍCH NHÂN TỐ EFA}

Bảng 3.5. Kết quả phân tích nhân tố khám phá

\begin{tabular}{|c|c|c|c|}
\hline \multirow{2}{*}{ Component } & \multicolumn{3}{|c|}{ Initial Eigenvalues } \\
\cline { 2 - 4 } & Total & \% of Variance & Cumulative \% \\
\hline 1 & 4.873 & 21.189 & 21.189 \\
\hline 2 & 3.443 & 14.969 & 36.158 \\
\hline 3 & 2.297 & 9.986 & 46.144 \\
\hline 4 & 1.663 & 7.231 & 53.375 \\
\hline 5 & 1.543 & 6.710 & 60.085 \\
\hline
\end{tabular}

Kết quả phân tích nhân tố khám phá (EFA - Exploratory Factor Analysis) ở bảng trên cho thấy tổng phương sai trích là $60,083 \%$ lớn hơn $50 \%$, điều này có nghĩa các nhân tố trích lại sẽ giải thích được $60,083 \%$ cho mô hình, còn lại 39,915\% sẽ được giải thích bởi những nhân tố khác. Tỷ số rút trích nhân tố (Eigenvalue) đều lớn hơn 1 nên được giữ lại.

Bảng 3.6. Kết quả phân tích nhân tố

\begin{tabular}{|c|c|c|c|c|c|c|}
\hline \multirow{2}{*}{ Code } & \multirow{2}{*}{ Biến quan sát } & \multicolumn{5}{|c|}{ Component } \\
\hline & & 1 & 2 & 3 & 4 & 5 \\
\hline $\mathrm{C} 4$ & $\begin{array}{l}\text { Doanh nghiệp này coi trọng các giá trị đạo đức trong kinh doanh hơn } \\
\text { những lợi ích nhầt thời khi giải quyết sự cồ phàn nàn từ phía khách } \\
\text { hàng }\end{array}$ & .801 & & & & \\
\hline $\mathrm{C} 5$ & Doanh nghiệp này có môi trường làm việc tốt cho người lao động & .795 & & & & \\
\hline $\mathrm{C} 7$ & Lãnh đạo doanh nghiệp hòa đồng và vui vẻ với mọi người & .793 & & & & \\
\hline $\mathrm{C} 2$ & Doanh nghiệp này có chất lượng sản phẩm/ dịch vụ tốt & .769 & & & & \\
\hline C3 & $\begin{array}{l}\text { Doanh nghiệp cung cấp thông tin trung thực trong các chương trình } \\
\text { quảng cáo }\end{array}$ & .759 & & & & \\
\hline C6 & Doanh nghiệp đối xử với khách hàng công bằng & .741 & & & & \\
\hline $\mathrm{C} 1$ & Doanh nghiệp này cung cấp đúng dịch vụ như đã cam kết & .658 & & & & \\
\hline E4 & Doanh nghiệp này có môi trường làm việc thân thiện với khách hàng & & .828 & & & \\
\hline E2 & Doanh nghiệp này có không gian môi trường làm việc xanh, sạch & & .824 & & & \\
\hline E1 & $\begin{array}{l}\text { Doanh nghiệp này có nhiều hoạt động trong việc nâng cao nhận thức } \\
\text { và bảo vệ môi trường }\end{array}$ & & .792 & & & \\
\hline E3 & $\begin{array}{l}\text { Doanh nghiệp này có môi trường làm việc an toàn (trang bị các thiết } \\
\text { bị chữa cháy, lối thoát hiểm, dụng cụ bảo hộ lao động v.v) }\end{array}$ & & .689 & & & \\
\hline D2 & $\begin{array}{l}\text { Doanh nghiệp này có nhiều hoạt động tài trợ giúp nâng cao nhận } \\
\text { thức trong cộng đồng }\end{array}$ & & & .827 & & \\
\hline D3 & $\begin{array}{l}\text { Doanh nghiệp này có nhiều đóng góp vào các dự án cải thiện "chất } \\
\text { lượng cuộc sông” của cộng đồng. }\end{array}$ & & & .742 & & \\
\hline D1 & $\begin{array}{l}\text { Doanh nghiệp này thường tham gia các hoạt động từ thiện như giúp } \\
\text { đỡ người khuyêt tật, trẻ em, người nghèo v.v }\end{array}$ & & & .740 & & \\
\hline D4 & $\begin{array}{l}\text { Doanh nghiệp này có nhiều chương trình tài trợ học bổng cho cộng } \\
\text { đồng }\end{array}$ & & & .725 & & \\
\hline A3 & Doanh nghiệp này duy trì lợi thế cạnh tranh tốt & & & & .786 & \\
\hline A4 & $\begin{array}{l}\text { Doanh nghiệp này có nhiều chính sách cải thiện hiệu quả hoạt động } \\
\text { kinh doanh và quản trị rủi ro }\end{array}$ & & & & .751 & \\
\hline
\end{tabular}


CỦA DOANH NGHIỆP TẠI THÀNH PHỐ HỒ CHÍ MINH

\begin{tabular}{|c|l|l|l|l|c|}
\hline $\mathrm{A} 2$ & $\begin{array}{l}\text { Doanh nghiệp này thường xuyên tăng cường công tác xúc tiến quảng } \\
\text { bá trên mạng xã hội nhằm giảm ngân sách quảng cáo, tiếp thị. }\end{array}$ & & .741 & \\
\hline $\mathrm{A} 1$ & $\begin{array}{l}\text { Doanh nghiệp ứng dụng công nghệ thông tin nhằm giảm chi phí và } \\
\text { thời gian phục vụ trực tiếp khách hàng }\end{array}$ & & .786 & \\
\hline $\mathrm{B} 2$ & Doanh nghiệp này có nhận thức về pháp luật tốt & & & & .789 \\
\hline $\mathrm{B} 1$ & $\begin{array}{l}\text { Doanh nghiệp này chấp hành pháp luật và thực hiện tốt các quy định } \\
\text { của địa phương }\end{array}$ & & & .749 \\
\hline $\mathrm{B} 3$ & $\begin{array}{l}\text { Doanh nghiệp này khuyến khích nhân viên của mình làm việc theo } \\
\text { đúng quy định của pháp luật }\end{array}$ & & & .695 \\
\hline $\mathrm{B} 4$ & $\begin{array}{l}\text { Doanh nghiệp này có nhiều hoạt động phổ biến, tuyên truyền pháp } \\
\text { luật tốt }\end{array}$ & & & .590 \\
\hline
\end{tabular}

Từ kết quả trên cho thấy mô hình phân tích nhân tố (EFA - Exploratory Factor Analysis) là phù hợp với dữ liệu, được tính thành 5 nhóm nhân tố và có thể sử dụng kết quả này cho phân tích hồi quy bội.

\section{Phân tích hồi quy}

Phương pháp phân tích hồi quy là sự nghiên cứu mức độ ảnh hưởng của một hay nhiều biến độc lập (independent variables) đến một biến phụ thuộc (dependent variables) nhằm dự báo biến kết quả dựa vào các giá trị được biết trước của biến giải thích. Để đo lường uy tín thương hiệu, tác giả tiến hành phân tích hồi quy tuyến tính bội và kiểm định các giả thuyết của mô hình với 5 nhóm yếu tố là biến độc lập để đo lường mức độ tác động của các nhóm yếu tố đến uy tín thương hiệu của các doanh nghiệp kinh doanh tại TPHCM. Kết quả nghiên cứu cho thấy mức độ ảnh hưởng của các yếu tố thể hiện qua hệ số hồi quy bội. Để so sánh mức độ tác động của các yếu tố chúng ta dùng hệ số hồi quy đã chuẩn hóa vì hệ số này không phụ thuộc thang đo. Như vậy, sử dụng phương trình hồi quy đã chuẩn hóa để phân tích mức độ ảnh hưởng của các yếu tố đến uy tín thương hiệu của các doanh nghiệp kinh doanh tại TPHCM.

Bảng 3.7. Summary model

\begin{tabular}{|c|c|c|c|c|c|c|c|c|c|c|}
\hline \multicolumn{11}{|c|}{ Model Summary } \\
\hline \multirow[t]{2}{*}{ Model } & \multirow[t]{2}{*}{$\mathrm{R}$} & \multirow{2}{*}{\begin{tabular}{|l}
$\mathrm{R}$ \\
Square
\end{tabular}} & \multirow{2}{*}{\begin{tabular}{|l|} 
Adjusted R \\
Square
\end{tabular}} & \multirow{2}{*}{$\begin{array}{l}\text { Std. Error } \\
\text { of the } \\
\text { Estimate }\end{array}$} & \multicolumn{5}{|c|}{ Change Statistics } & \multirow[t]{2}{*}{ Durbin-Watson } \\
\hline & & & & & $\begin{array}{l}\text { R Square } \\
\text { Change }\end{array}$ & F Change & df1 & df 2 & $\begin{array}{l}\text { Sig. F } \\
\text { Change }\end{array}$ & \\
\hline 1 & $.719^{a}$ & .517 & .505 & .747 & .517 & 46.176 & 5 & 216 & .000 & 1.742 \\
\hline
\end{tabular}

Bảng trên cho thấy hệ số tương quan hiệu chỉnh: $\mathrm{R} 2=0,517$ (kiểm định $\mathrm{F}$, sig. $<0,05$ ); có nghĩa là $51,7 \%$ sự thay đổi của biến Y được giải thích bởi sáu biến độc lập (Xi). Hệ số Durbin - Watson $(\mathrm{d})=1,742$; số quan sát $\mathrm{n}=222$, tham số $\mathrm{k}=5$, mức ý nghĩa 0,01 (99\%), trong bảng thống kê Durbin - Watson, $\mathrm{dL}$ (trị số thống kê dưới $)=1,623$ và $\mathrm{dU}$ (trị số thống kê trên) $=1,725$. Vậy ta có: $(\mathrm{dL}=1,623)<(\mathrm{d}=1,742)<[4-$ $(\mathrm{dU}=1,725)=2,275$ ] chứng tỏ mô hình không có hiện tượng tự tương quan

Bảng 3.8. ANOVA

\begin{tabular}{|l|l|l|l|l|l|l|}
\hline \multicolumn{2}{|l|}{ ANOVA $^{\text {a }}$ Model } & Sum of Squares & df & Mean Square & F & Sig. \\
\hline \multirow{3}{*}{1} & Regression & 129.056 & 5 & 25.811 & 46.176 & $.000^{\mathrm{b}}$ \\
\cline { 2 - 8 } & Residual & 120.738 & 216 & .559 & & \\
\cline { 2 - 7 } & Total & 249.794 & 221 & & & \\
\hline
\end{tabular}


Kết quả kiểm định có giá trị $\mathrm{F}=46,176$ và Sig. $=0,000<0,05$ cho thấy mô hình xây dựng là phù hợp với tập dữ liệu và các biến đưa vào mô hình đều có liên hệ với biến phụ thuộc. Nói chung, phân tích hồi quy với độ tin cậy được chọn là $95 \%$, tương ứng với các biến được chọn với mức ý nghĩa thống kê là $\mathrm{p}$ $<0,01$; kết quả cho thấy tất cả các biến đều thỏa mãn theo nhu cầu. Kiểm định sự phù hợp của mô hình cho thấy hiện tượng đa cộng tuyến không vi phạm $(\mathrm{VIF}<10)$

Bảng 39. Các yếú tố tác động đến uy tín thương hiệu của các DN

\begin{tabular}{|c|c|c|c|c|c|c|c|c|c|c|}
\hline \multicolumn{11}{|c|}{ Coefficients $^{\mathrm{a}}$} \\
\hline \multirow{2}{*}{\multicolumn{2}{|c|}{ Model }} & \multicolumn{2}{|c|}{\begin{tabular}{|l} 
Unstandardized \\
Coefficients
\end{tabular}} & \multirow{2}{*}{\begin{tabular}{|l|}
$\begin{array}{l}\text { Standardized } \\
\text { Coefficients }\end{array}$ \\
Beta \\
\end{tabular}} & \multirow[t]{2}{*}{$t$} & \multirow[t]{2}{*}{ Sig. } & \multicolumn{2}{|c|}{$\begin{array}{l}\text { 95.0\% Confidence } \\
\text { Interval for B }\end{array}$} & \multicolumn{2}{|c|}{$\begin{array}{l}\text { Collinearity } \\
\text { Statistics }\end{array}$} \\
\hline & & $\mathrm{B}$ & \begin{tabular}{|l|} 
Std. \\
Error \\
\end{tabular} & & & & $\begin{array}{l}\text { Lower } \\
\text { Bound }\end{array}$ & \begin{tabular}{|l|} 
Upper \\
Bound \\
\end{tabular} & Tolerance & VIF \\
\hline \multirow[t]{6}{*}{1} & (Constant) & .2979 & .487 & & 6.120 & .000 & & & & \\
\hline & $\mathrm{X} 1$ & .630 & .074 & .427 & 8.536 & .000 & .542 & .502 & .893 & 1.120 \\
\hline & $\mathrm{X} 2$ & .380 & .081 & .240 & 4.668 & .000 & .444 & .303 & .847 & 1.181 \\
\hline & $\mathrm{X} 3$ & .425 & .094 & .231 & 4.502 & .000 & .371 & .293 & .848 & 1.180 \\
\hline & $\mathrm{X} 4$ & .264 & .070 & .195 & 3.762 & .000 & .402 & .248 & .831 & 1.203 \\
\hline & $\mathrm{X} 5$ & .176 & .085 & .100 & 2.063 & .040 & .138 & .139 & .948 & 1.055 \\
\hline
\end{tabular}

Kết quả phân tích hồi quy cho thấy các yếu tố tác động đến uy tín thương hiệu và thể hiện mức độ ưu tiên như sau: (1) Trách nhiệm về đạo đức: $\beta=0,427$; (2) Trách nhiệm về pháp luật: $\beta=0,240$; (3) Trách nhiệm về từ thiện: $\beta=0,231$; (4)Trách nhiệm về môi trường: $\beta=0,195$; $(5)$ Trách nhiệm về kinh tế: $\beta=$ 0,100 . Phương trình hồi quy có dạng như sau: $\mathrm{Y}=0,427 \mathrm{X} 1+0,240 \mathrm{X} 2+0,231 \mathrm{X} 3+0,195 \mathrm{X} 4+0,100 \mathrm{X} 5$. Kết quả nghiên cứu này kết luận các nhân tố thuộc trách nhiệm xã hội của doanh nghiệp tác động đến thương hiệu của doanh nghiệp kinh doanh tại TPHCM. Kết quả nghiên cứu này chính là cơ sở đề xuất các kiến nghị các giải pháp nhằm nâng cao uy tín và thương hiệu của doanh nghiệp.

\section{KẾT LUẬN VÀ HÀM Ý QUẢN TRI}

\subsection{Kết luận}

Nghiên cứu này cho thấy sự tác động của các chính sách xã hội đến thương hiệu của doanh nghiệp kinh doanh tại TPHCM và mức độ ảnh hưởng của từng nhân tố là khác nhau.

Kết quả nghiên cứu này thực hiện được các mục tiêu như sau: Thứ nhất, xác định được các nhân tố tác động đến thương hiệu của doanh nghiệp kinh doanh tại TPHCM; Thứ hai, xác định được thứ tự ưu tiên mức độ tác động các nhân tố đến thương hiệu của doanh nghiệp kinh doanh tại TPHCM; Thứ ba, đề xuất các nhóm giải pháp nhằm nâng cao uy tín thương hiệu của các doanh nghiệp kinh doanh tại TPHCM trong xu thế cạnh tranh hội nhập trong lương lai. Theo kết quả phân tích, năm nhân tố trên đều có tác động tương quan thuận đến thương hiệu của các doanh nghiệp kinh doanh tại TPHCM, theo thứ tự lần lượt là: trách nhiệm về đạo đức, trách nhiệm về pháp luật, trách nhiệm về từ thiện, trách nhiệm về môi trường, trách nhiệm về kinh tế. Đây là cơ sở quan trọng để các doanh nghiệp xem xét về chiến lược phát triển kinh doanh của mình trong thời gian tới.

\subsection{Hàm ý quản trị}

\subsubsection{Trách nhiệm về đạo đức}

Các doanh nghiệp kinh doanh tại TPHCM cần nâng cao thương hiệu của mình thông qua việc cung cấp sản phẩm, dịch vụ chất lượng đúng như đã cam kêt; xây dựng môi trường làm việc tốt, an toàn, thân thiện, minh bạch và công bằng cho người lao động; nâng cao nhận thức trong toàn thể doanh nghiệp về việc coi trọng các giá trị đạo đức trong kinh doanh và xem đây là chìa khóa để nâng cao thương hiệu của doanh nghiệp trong tâm trí khách hàng.

\subsubsection{Trách nhiệm về pháp luật}


Các doanh nghiệp tại TPHCM cần duy trì việc tăng cường hoạt động phổ biến tuyên truyền pháp luật để toàn thể doanh nghiệp có nhận thức đúng về luật pháp. Bên cạnh đó, cần có những hình thức khuyến khích, động viên và khen thưởng cho những nhân viên trung thực với khách hàng và làm việc theo đúng quy định của pháp luật.

\subsubsection{Trách nhiệm về tù̀ thiện}

Để nâng cao thương hiệu trong tâm trí khách hàng, các doanh nghiệp cần tích cực tham gia các hoạt động từ thiện như giúp đỡ người khuyết tật, trẻ em, người nghèo; tăng cường đóng góp cho các dự án cải thiện chất lượng cuộc sống cho cộng đồng người nghèo; tài trợ cho các chương trình nâng cao nhận thức trong cộng đồng.

\subsubsection{Trách nhiệm về môi trường}

Các doanh nghiệp tại TPHCM cần phải xây dựng môi trường làm việc văn hóa, văn minh và hiện đại theo hướng xanh, sạch và thân thiện không chỉ đối với khách hàng của mình mà còn đối với nhân viên vì nhu cầu của con người ngày càng cao. Những nhân viên hài lòng sẽ gắn bó và trung thành với doanh nghiệp. Khi trung thành họ sẽ toàn tâm toàn ý với doanh nghiệp. Các doanh nghiệp tại TPHCM cần xem nhân viên của mình "như thượng đế" vì chính họ sẽ biến "khách hàng là thượng đế".

\subsubsection{Trách nhiệm về kinh tế}

Các doanh nghiệp kinh doanh tại TPHCM cần xây dựng các chính sách giảm chi phí như ứng dụng công nghệ thông tin nhằm giảm thời gian phục vụ trực tiếp khách hàng, thực hiện các hoạt động xúc tiến quảng bá trên mạng trực tuyến, mạng xã hội, thay vì quảng cáo và tiếp thị tốn nhiều chi phí. Những việc làm như vậy không chỉ giúp tối đa hóa lợi nhuận cho doanh nghiệp và cho các cổ đông, mà còn tạo ra nhiều giá trị gia tăng cho khách hàng, làm tăng thương hiệu của doanh nghiệp trong tâm trí của khách hàng, giúp xây dựng khách hàng trung thành.

\section{TÀI LIỆU THAM KHẢO}

[1] Chester Barnard (1938), The Functions of the Executive. Harvard University Press, 1938

[2] J. M. Clark's (1933) Social Control of Business, University of Chicago Press, 1933

[3] Theodore Kreps's (1940). Measurement of the Social Performance of Business. U.S. Government Printing Office.

[4] H.R. Bowen. Social Responsibilities of the Businessman, Oxford University Press \& New York, 1953

[5] Shafiqur Rahman, Evaluation of Definitions: Ten Dimensions of Corporate Social Responsibility. World Review of Business Research Vol. 1. No. 1. March 2011

[6] Archie B. Carroll. A Three-Dimensional Conceptual Model of Corporate Performance.The Academy of Management Review. Vol. 4, No. 4, pp. 497-505, 1979

[7] http://dantri.com.vn/kinh-doanh/co-74-ty-usd-ong-chu-facebook-mark-zuerberg-tieu-tien-nhu-the-nao20171022194949002.htm. Dan trí, 22/10/2017

[8] Philip Kotler. Principles of Marketing. Prentice Hall, 2010

[9] Hoàng trọng và Chu Nguyễn Mộng Ngọc (2008). Phân tích dữ liệu nghiên cứu với SPSS. NXB Hồng Đức.

[10] Hair \& ctg (1998), Multivariate Data Analysis, Prentice-Hall International.

Ngày nhận bài: 22/11/2017

Ngày chấp nhận đăng: 12/01/2018 